\title{
Challenges in assessing the environmental consequences of dietary changes
}

\author{
Stefano Cucurachi ${ }^{1} \cdot$ Yi Yang $^{1,2} \cdot$ Joseph D. Bergesen $^{1} \cdot$ Yuwei Qin $^{1}$. \\ Sangwon Suh $^{1}$
}

Published online: 7 April 2016

(c) Springer Science+Business Media New York 2016

\begin{abstract}
Tom et al. (Environ Syst Decis 1-12, 2015) compared the energy requirements, water footprint, and greenhouse gas emissions of diet regimens recently recommended by the US Department of Agriculture. This editorial comments on a number of challenges related to the use of the results of life-cycle assessment studies to quantify the environmental impacts of dietary shifts.
\end{abstract}

Keywords Life cycle assessment · Dietary change .

Marginal impact · Meta-analysis

\section{Introduction}

Tom et al. (2015; the authors hereafter) compared the energy requirements, water footprint, and greenhouse gas (GHG) emissions of diet regimens recently recommended by the US Department of Agriculture (USDA). The authors found that following a recommended USDA diet with reduced meat intake and increased dairy, seafood, and vegetables would result in an increase of life-cycle energy demand, water consumption, and GHG emissions by 38 , 10 , and $6 \%$, respectively. The study used a comprehensive meta-analysis of existing life-cycle assessment (LCA) studies to quantify the environmental impacts of alternative

Sangwon Suh

suh@bren.ucsb.edu

1 Bren School of Environmental Science and Management, 2400 Bren Hall, University of California, Santa Barbara, CA 93106-5131, USA

2 CSRA Inc., 3170 Fairview Park Drive, Falls Church, VA 22042, USA diets. The authors rightly raised attention to the environmental impacts of food choices.

Unfortunately, media outlets around the globe took the liberty to loosely translate the authors' scientific findings as "lettuce produces more GHG than bacon does" (Rea 2015), although such a comparison does not appear in Tom et al. (2015). As a number of comments were already made to the lettuce versus bacon comparison in the media, this commentary focuses on some of the methodological issues related to the use of LCA for understanding the implications of dietary changes.

\section{Is average impact the same as marginal impact?}

The method used by the authors to calculate life-cycle environmental impacts of food consumption before dietary change $\left(I_{\text {before }}\right)$ and that after dietary change $\left(I_{\text {after }}\right)$ can be simplified for the case of two food categories as Eqs. (1) and (2), respectively. The model the authors employed was more complex, as it also involved caloric intake through multiple food sources including vegetables, meat, fish, and dairy. Here the method is reduced to the case of only two food categories for the sake of simplicity. Let us consider the following:

$I_{\text {before }}=\left[f_{\text {veg }} \times x_{\text {before }}+f_{\text {meat }} \times\left(1-x_{\text {before }}\right)\right] \times c$
$I_{\text {after }}=\left[f_{\text {veg }} \times x_{\text {after }}+f_{\text {meat }} \times\left(1-x_{\text {after }}\right)\right] \times c$.

In Eqs. (1) and (2), $f_{\text {veg }}$ and $f_{\text {meat }}$ represent environmental impacts (e.g., blue water consumption) per calorie of vegetables and meat, respectively; $x_{\text {before }}$ is the fraction of vegetables in caloric intake and $1-x_{\text {before }}$ the fraction of meat in caloric intake; $x_{\text {after }}$ is the fraction of vegetables in caloric intake and $1-x_{\text {after }}$ the fraction of meat in 
caloric intake after the dietary pattern change; $c$ is the total caloric intake per person before the dietary pattern change. If the dietary pattern shifts toward a higher caloric intake through vegetables, $x_{\text {after }}$ will be larger than $x_{\text {before. }}$. In this case, if an environmental impact (e.g., blue water consumption) per calorie of vegetables $\left(f_{\mathrm{veg}}\right)$ is larger than that of meat $\left(f_{\text {meat }}\right)$, then the environmental impact of food consumption after the dietary pattern change will be higher than before (i.e., $I_{\text {after }}>I_{\text {before }}$ ).

An implicit assumption in this calculation is that $f_{\mathrm{veg}}$ and $f_{\text {meat }}$ remain constant in the process of dietary pattern change. That is to say, the authors assumed that, for example, blue water consumption per calorie of the additional vegetables required due to the dietary pattern change will be the same as that of the currently consumed vegetables. Currently, California produces a majority of vegetables consumed in the USA relying largely on irrigated water. Therefore, it becomes easily possible that blue water consumption per calorie of average meat, which relies largely on Midwest corn, is lower than that of average vegetable.

An important but untested question is whether the lifecycle environmental impacts of foods to be produced as a result of the dietary pattern change will be the same as those of average foods that are currently produced. In general, additional demand is absorbed by the producer with least marginal costs, which may exhibit significantly different environmental profiles as compared to the average producer. In LCA literature, this is referred to as the marginal vs. average production technology issue (Weidema et al. 1999; Dalgaard et al. 2008; Schmidt 2008; Lund and Mathiesen 2010; Yang and Suh 2015a, b). For example, Yang and Suh (2015a) examined the carbon payback time of corn ethanol considering marginal yield. In a nutshell, carbon payback time of corn ethanol is the number of years needed to balance the upfront GHG emissions due to land transformation for additional corn with recurring annual reduction of GHG emissions by replacing gasoline. Carbon payback time of corn ethanol was previously estimated to be about 40-48 years using average data. Yang and Suh (2015a), however, show that corn ethanol may never be able to pay back the upfront GHG emissions if the yield of marginal corn production is $60 \%$ or below that of the average cornfield currently cultivated. Yang and Suh (2015b) also show that the expansion of corn due to increased demand for ethanol in Southern states creates very different emission profiles for marginal corn as compared to average corn.

Therefore, quantifying how a dietary shift toward more vegetables, fruits, dairy, and fish/seafood would affect the environment requires an understanding of how and where these additional foods will be produced. In Tom et al. (2015), however, the authors utilized average data to quantify marginal changes in environmental impacts, resulting in an inconsistency between the methods used and the goals of the study.

\section{Can a mere collection of the literature serve as a representative $L C A$ result?}

The authors' study also raises questions in regard to the use of meta-analysis. The authors collected and documented a considerable amount of data related to food LCA studies. In disciplines such as the medical sciences, a meta-analysis allows screening the literature and comparing results in the hope of finding trends and devising the first evidence of cause-effect mechanisms. The need for the standardization of LCA meta-analyses was identified by an ad hoc special issue of the Journal of Industrial Ecology in 2012 (see, e.g., Zumsteg et al. 2012). The resulting STARR-LCA approach is based on the Preferred Reporting Items for Systematic Reviews and Meta-Analyses (PRISMA) model for metaanalysis used in the biomedical sciences. Even though the approach may be further improved, the STARR-LCA model provides a more plausible basis for assessing and reporting on LCA studies and to judge on their potential biases and limitations. The STARR-LCA model was later applied to a number of meta-analyses of LCA studies such as LCA harmonization study for electricity generation technologies (Heath and Mann 2012).

The necessity to define criteria to screen and review studies is not trivial. Different LCA studies may use different assumptions, system boundaries, and have different data quality. For instance, LCA studies often use data that either are global averages (e.g., urban area high population density) or refer to a specific geographical location (e.g., Santa Barbara, CA). Often the results generated for one case study are, thus, specific to the conditions under which they are produced. Furthermore, LCAs for agricultural products are particularly sensitive to geographical system boundaries and can rarely be generalized to other geographies, meaning that careful screening is needed to check whether the data are compatible (Yang and Suh 2015b).

Related to the specificity of LCA studies, the topic of food waste is an important consideration for the case of food production. If a greater portion of a particular food is wasted, then a greater impact is attributed to the portion of the food that is consumed. The authors rightly account for food losses using data sources from the USDA (Muth 2011), but there are a few possible considerations that could influence the results of the study. As earlier mentioned, LCA studies have varying system boundaries, with the implication that food waste may already be accounted for in some studies, but not in others among the pool of literature that the authors considered. This variability in 
system boundary means that the impact of producing wasted food could be double-counted in some cases. Food loss can occur at every stage in the life cycle of a food item, from the crop production itself to transportation, at retail, and at the consumer (Parfitt et al. 2010). The system boundary of some studies is a cutoff at the producer's gate, while others might include just retail or include the consumer stage (e.g., food going bad in the refrigerator before it can be eaten). This problem again highlights the need of using a harmonized approach to meta-analyses of LCA studies.

\section{Concluding remarks}

The authors conducted a comprehensive meta-analysis that deals with the important issue of food and dietary choices, and of how changes thereof can affect the related environmental impacts. We elaborated on some of the challenges that exist in quantifying the impact of large-scale dietary shifts. In particular, even though the literature on marginal production technologies in LCA has a long history, operational tools to quantify marginal impacts are still evolving, and marginal data are not always available (Suh and Yang 2014). Thus, additional research is needed to better understand large-scale changes and their associated environmental impacts. This contention is valid not only for the analysis of the life cycle of food systems, but also for any other life cycle for which the consequences of change are under assessment. Furthermore, we highlighted a number of issues when generalizing the results of LCA studies. Beyond the mentioned attempt to standardize meta-analysis in LCA, a protocol for mining data from LCA studies considering completeness, system boundary, underlying assumptions, and quality is needed (see, e.g., the effort of the UNEP-SETAC on knowledge mining guidance UNEP 2012).

Acknowledgments This research was supported in part by the National Science Foundation (NSF) under the grant numbers, 1360445 (JB, SS) and 1331438 (YI), and by the Environmental
Protection Agency (EPA) under the STAR Grant, No. 83557901 (SC, YQ, SS).

\section{References}

Dalgaard R, Schmidt J, Halberg N et al (2008) LCA of soybean meal. Int J Life Cycle Assess 13:240-254

Heath G, Mann M (2012) Background and reflections on the life cycle assessment harmonization project. J Ind Ecol 16:S8-S11

Lund H, Mathiesen B (2010) Energy system analysis of marginal electricity supply in consequential LCA. Int J Life Cycle Assess $15: 260-271$

Muth M (2011) Consumer-level food loss estimates and their use in the ERS loss-adjusted food availability data. Accessed 21 Jan 2016

Parfitt J, Barthel M, Macnaughton S (2010) Food waste within food supply chains: quantification and potential for change to 2050 . Philos Trans R Soc Lond B Biol Sci 365:3065-3081

Rea S (2015) Vegetarian and "healthy" diets could be more harmful to the environment. In: Carnegie Mellon Univ. News. http:// www.cmu.edu/news/stories/archives/2015/december/diet-andenvironment.html. Accessed 1 Jan 2016

Schmidt J (2008) System delimitation in agricultural consequential LCA. Int J Life Cycle Assess 13:350-364

Suh S, Yang Y (2014) On the uncanny capabilities of consequential LCA. Int J Life Cycle Assess 19:1179-1184

Tom M, Fischbeck P, Hendrickson C (2015) Energy use, blue water footprint, and greenhouse gas emissions for current food consumption patterns and dietary recommendations in the US. Environ Syst Decis 36(1):1-12

UNEP (2012) Knowledge mining guidance. In: http://www.life cycleinitiative.org/activities/phase-iii/knowledge-mining-guidance/. Accessed 21 Jan 2016

Weidema B, Frees N, Nielsen A (1999) Marginal production technologies for life cycle inventories. Int $\mathrm{J}$ Life Cycle Assess 4:48-56

Yang Y, Suh S (2015a) Marginal yield, technological advances, and emissions timing in corn ethanol's carbon payback time. Int J Life Cycle Assess 20:226-232

Yang Y, Suh S (2015b) Land cover change from cotton to corn in the USA relieves freshwater ecotoxicity impact but may aggravate other regional environmental impacts. Int J Life Cycle Assess 20:196-203

Zumsteg JM, Cooper JS, Noon MS (2012) Systematic Review Checklist: a standardized technique for assessing and reporting reviews of life cycle assessment data. J Ind Ecol 16:S12-S21. doi:10.1111/j.1530-9290.2012.00476.x 